\title{
Analysis of the Qualities Matching New Classification of Clinical Pharmacist
}

\author{
F. U. KHAN, N. WAQAS, A. U. IHSAN, P. KHONGORZUL1', J. WAZIR, W. GANG, Y. MENGQI, L. XIAOQIAN, L. HAN² AND \\ ZHOU XIAOHUI $1,3,4^{*}$
}

Department of Clinical Pharmacy, School of Basic Medicine and Clinical Pharmacy, ${ }^{1}$ Department of Microbiology and Biochemical Pharmacy, School of Life Science, China Pharmaceutical University, Nanjing, Jiangsu Province, 211198, People's Republic of China, ${ }^{2}$ Department of Pharmacy, ${ }^{3}$ Department of Surgery, Nanjing Shuiximen Hospital, Nanjing, Jiangsu Province, ${ }^{4} Z$ hongda Hospital, Affiliated with Southeast University, China

\section{Farhan, et al.: Clinical Pharmacist Classification and Qualities}

\begin{abstract}
Clinical pharmacy, a lifesaving profession that was traditionally related to compounding and dispensing of medicine has now shifted to more patient-centered activities such as pharmaceutical care. A clinical pharmacist could better provide this service as he/she is directly related to patient care. In this review, clinical pharmacists were classified into three stages, learning, applied and creative pharmacist so that he/ she can provide better services to the patient. Furthermore, the qualities, which are essential for the clinical pharmacist to be a competent person including strong medical science background, good communication skills, up-to-date knowledge, creativity and innovation, advanced clinical skills, leadership, behavior and social expectations, and intellectual ability were also discussed. The aim of this review is to make the clinical pharmacists aware of their role and responsibilities at each stage, to fulfill these roles effectively rectifying the flaws at each stage by identifying solutions. Moreover, acquiring these qualities specified in this review, it would help clinical pharmacist to transform into a competent health care provider leading to provision of better health care services.
\end{abstract}

Key words: Clinical pharmacist, classification, stages, competency, qualities

Pharmacy is a lifesaving profession, which was related to only compounding and dispensing of medications in the beginning but now it also included more modern services related to health. For that reason, the pharmacy has had to adjust to cover all health-related aspects. Over several centuries, the pharmacy has shifted from the traditional role of compounding and dispensing of medicine to more patient-related activities, such as patient care ${ }^{[1,2]}$. The idea of pharmacy practice to focus on patient care was first presented by Hepler and Strand ${ }^{[3]}$ as pharmaceutical care, which they defined as "the responsible provision of medication therapy which will improve patient's quality of life and will help in achieving definite outcomes". It involves a process through which pharmacist co-operates with the patient and other health care professionals in designing, monitoring and implementing a therapeutic plan that will produce specific therapeutic outcomes for the patient.

Pharmacy practice has played a very important role in building the trust of patients on the health care

*Address for correspondence

E-mail: zhxh@cpu.edu.cn

January-February 2019 system, reducing treatment cost, achieving better health outcomes, reducing the risk of treatments and side effects of medication, safe access to the treatment and improved quality of life in many countries ${ }^{[4]}$. In recent years, the clinical pharmacy has focused on patient-centred care rather than their traditional role of dispensing and compounding of medicines ${ }^{[5]}$ and optimizing the safety of patients throughout the medication management process ${ }^{[6]}$. In 2005, the American College of Clinical Pharmacy defined clinical pharmacy as the "area of pharmacy concerned with the science and practice of rational medication use"[7]. This field of pharmacy practice does not focus only on medicines but also on patient-oriented services $^{[8]}$. Clinical pharmacists are the personnel who

This is an open access article distributed under the terms of the Creative Commons Attribution-NonCommercial-ShareAlike 3.0 License, which allows others to remix, tweak, and build upon the work non-commercially, as long as the author is credited and the new creations are licensed under the identical terms

Accepted 03 November 2018

Revised 16 September 2017

Received 09 February 2017

Indian J Pharm Sci 2019;81(1):2-10 
give scientifically valid information regarding the safe, appropriate, adverse drug reaction and cost-effective use of medications ${ }^{[7,9-11]}$.

From the past few years, the clinical pharmacy has spread out drastically in terms of its professional services in many countries. Now a days, the clinical pharmacy profession is one of the most important professions in the multidisciplinary setup of health care, especially in the hospital ${ }^{[12]}$. The clinical pharmacist plays a crucial role in different health care setups by evaluating and revising the medicines, medication history, dispensing errors, administration errors, analysing drug interactions, pointing out the adverse drug reactions, exhorting individualization of dosage regimen and contributing to patients counselling. By participation in clinical discussions and ward rounds, the clinical pharmacists can help in identifying, preventing and reducing drug interactions and other drug-related problems ${ }^{[13]}$.

Till now, many attempts have been made to classify pharmacists according to their respective departments such as clinical pharmacist, hospital pharmacist, academic pharmacist, ambulatory pharmacist, community/retail pharmacist, compounding pharmacist, government pharmacist, home care pharmacist, independent pharmacist, industrial pharmacist, managed care pharmacist, nuclear pharmacist and oncology pharmacist ${ }^{[14]}$. However, it is proposed that clinical pharmacist is classified into three stages; learning pharmacist, applied pharmacist and creative pharmacist. This classification is specifically for clinical pharmacists and the question is, why need such a classification? This classification is necessary since a clinical pharmacist at these three stages has different roles and responsibilities that need to be elaborated. The fact is that not all clinical pharmacists perform these roles and responsibilities to the required level. Therefore, a need also arose to describe the qualities that a clinical pharmacist needs to acquire in order to be competent to carry out his/her role and responsibilities proficiently. These qualities include, a strong medical science background, good communication skills, leadership, creativity, and innovation. The purpose of this review was to address the differences between these three stages of a clinical pharmacist and the roles at each stage and how a clinical pharmacist be promoted from a learner to a creative pharmacist. In addition, the basic characteristics that are necessary for being a competent clinical pharmacist were discussed.

\section{Stages of clinical pharmacist:}

In this review, clinical pharmacists were classified into three stages i.e. learning, applied and creative clinical pharmacist based on duration of work experience and skills. Although, these three stages could be applied to all other classes of pharmacists in general, a greater focus specifically on the clinical pharmacist was given so that one could easily understand the responsibilities of a clinical pharmacist at each stage (fig. 1).

\section{Stage-I, learning pharmacist:}

Learning can be defined as "gaining knowledge and skills or change in someone performance by studying or practicing, so that the learner can achieve their task easily, which he or she had not achieved previously" ${ }^{[15,16]}$. While a learning pharmacist is the one who learns about the pharmacy by gaining knowledge, skills, and training in the pharmacy institution and then utilizing its knowledge and skills for the better provision of health care to the society. For the provision of safe medication use and health care systems, the role of clinical pharmacist is essential because he is a vital part of the health care team ${ }^{[17]}$. Therefore, it is imperative to provide students with good knowledge and skills through learning so that they can become a competent clinical pharmacist ${ }^{[18-20]}$. One of the most difficult challenges confronting schools of pharmacy is to educate pharmacy students today for tomorrow's need. For students to pursue a career as a clinical pharmacist, they have to study about the pharmacy for $5 \mathrm{y}$ or more depending on the institution. The curriculum of clinical pharmacy students typically include courses in the area such as pharmacology, pharmaceutical care, laboratory services and management and also include a clinical internship. It is the responsibility of the pharmacy council or boards in respective countries to keep the curriculum of pharmacy education up-to-date to train the pharmacists for the future role, which they will perform in different healthcare environments ${ }^{[21]}$.

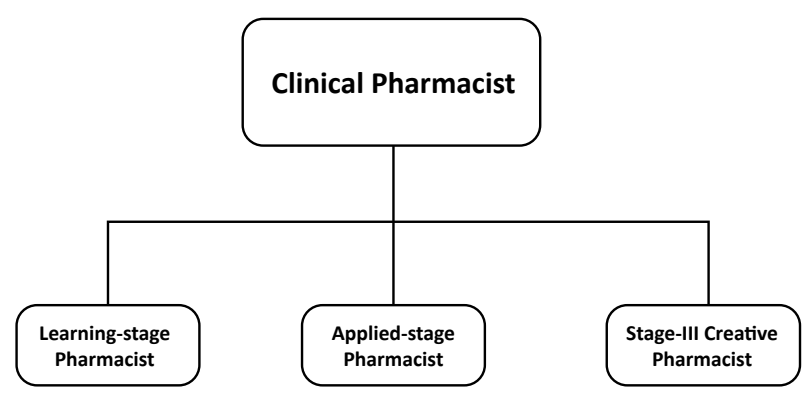

Fig. 1: Schematic of clinical pharmacist stages Classification based on duration of work experience and skills 
To do their job well, students have the responsibility to actively take part in all curricular activities, experiments and should show their interest in the clinical internship. It is also necessary for pharmacy students to grasp some skills and knowledge upon graduation ${ }^{[22]}$. Moreover, it is mandatory for pharmacy educational institutions to build such skills and knowledge to their students during their under graduation.

Clinical pharmacists after completing their degrees need to start a job to acquire skills and experience. They have to work under the supervision of a senior clinical pharmacist (applied pharmacist). Clinical pharmacists in this category have gained an experience of nearly $5 \mathrm{y}$ and are at the learning stage. Due to the high level of competency, it is difficult for the graduated clinical pharmacist to attain a suitable job ${ }^{[23]}$ because of the factors such as lack of training, knowledge, skills, poor clinical decisions, innate personality traits and poor mentorship by senior pharmacists ${ }^{[24]}$. Therefore, a clinical pharmacist must acquire necessary skills and knowledge through proper training and hard work under the supervision of a competent senior clinical pharmacist so that they can compete with the challenging economic and health care environment ${ }^{[25]}$. The overall training of clinical pharmacist should not involve only studying about pharmacology, patient care, and dealing with staff members but learning about cultural, ethical, social, legal and economic principles that are essential for the provision of patient care ${ }^{[26]}$.

\section{Stage-II, applied pharmacist:}

Clinical pharmacist in this category has practical experience of around 5-10 y in general. This kind of pharmacist is also called the senior pharmacist. They are experts and have good knowledge about their work, which they gained through practical training and lifelong learning. Their presence is very crucial for any kind of organization because they are proficient in their work. They have various kinds of responsibilities such as acting as a supervisor to train the freshly graduated pharmacists, providing prescribing advice to the medical and nursing staff. They are a specialist in evaluating and revising the medication history, dispensing errors, administration errors, analysing drug interaction, exhorting individualization of dosage regimen and patient counselling. As applied pharmacists have sound knowledge about drugdrug interaction, drug-food interaction, adverse drug reaction, dose adjustment, medication monitoring, patient counselling and good interaction with physicians, therefore, they can help in reducing medication errors and minimizing the communication gap between the patient and physician ${ }^{[12]}$. Some previously published studies also showed that applied pharmacist can take more accurate medication histories, which were traditionally done by junior doctors ${ }^{[27,28]}$.

These pharmacists are in between learning and creative stage. They are professional in their field but mostly provide formal services, which they acquired in their entire life. Although applied pharmacists are experts in their work but are deficient in creativity. The reason for inadequacy in creativity is that they not go beyond routine and standard approaches to their responsibilities. They lack abilities to analyse the factors contributing to the unwanted situation, and generating a set of alternative interventions to achieve their goals. In most cases, they fall short of the competence required to address a task or challenge with innovative or divergent thinking and so on. This is the most important and a critical turning stage for clinical pharmacist because, at this stage, clinical pharmacist starts to develop creativity and innovation in his/her work by utilizing their work experience as in most cases, creativity comes after long-term experience. Therefore, there is a prerequisite to enhance creativity in applied pharmacist and so need to elaborate how creativity can be augmented.

\section{Stage-III, creative pharmacist:}

Creativity is the process of generating new ideas whilst innovation is the shifting, refining, and most critically the implementation of those ideas. For successful innovation, creativity is a necessary precondition ${ }^{[29]}$. The application of existing knowledge and the development of appropriate new knowledge are required for creativity and innovation ${ }^{[30]}$. Similarly, like other health care professionals, clinical pharmacists are also exerting efforts in the field of creativity and innovation.

According to the present classification, a clinical pharmacist in this category has experience of more than ten years and has the quality of creativity and innovation. Pharmacists in this category do not only perform their daily and routinely work effectively but also be able to create and give some new ideas related to their work. For example, if applied and creative clinical pharmacists were compared, the big difference noticeable between these two is that, applied pharmacist will just be able to perform their services in the way, which they adopted and learned during their 
professional pharmacy career. Conversely, creative pharmacists will not only perform their services proficiently but will also give some new ideas about their work in order to bring modification or complete change in the pre-existing services or treatment such as, change in the treatment plan, introduction of novel therapeutic regimen and protocols, discovery of new drug, innovation of new services like pharmaceutical care and so on.

Creativity of a clinical pharmacist can be enhanced by brainstorming, thinking outside the box, accepting the challenges, developing treatment plans, new ways to improve communication in relationships, taking multiple perspectives on a problem and knowledge acquisition. Besides these, clinical pharmacist need to be persistent, energetic, enthusiastic, having good social and political skills, being attracted by the challenge of the work/problem, being oriented towards doing things differently and taking risks, having intellectual honesty, tactics for creative thinking, having diverse experience, excited by the work itself, and having good problems solving abilities. If clinical pharmacist will have these distinguished qualities, then he/she will be able provide novelty in their work. For the clinical pharmacists to perform their role effectively at each stage there is a prerequisite of some basic qualities that would enhance their abilities to provide better health care services.

\section{How to become a competent clinical pharmacist:}

Because of the expanding volume and complexity of drug therapy, ensuring the safe use of medications and the high cost of drugs, the clinical pharmacist is in high demand ${ }^{[31]}$. There is high job turnover for clinical pharmacist because of the increased stress, increased financial compensation and heavy workload that leads to deterioration of the pharmacist's work environment ${ }^{[32]}$. To perform their roles and responsibilities to the best at the three different stages that was discussed earlier, a clinical pharmacist should have the qualities of competency.

A "competency" is a "distinct skill, ability or attitude which is necessary for one to be competent in his/her profession" [33]. "Competence" as recognized by the Council on Credentialing in Pharmacy, is "the ability of a person to make accurate decisions, interact with a physician, nurses, and other colleagues appropriately and perform their duties at their best" ${ }^{[34]}$. While professional competence is characterized by good decision-making abilities, a sound knowledge, having good problem-solving skills and expert in dealing with diverse patient care situations.

Clinical pharmacists are licensed pharmacists who are expert in their field and have specialized advance knowledge and training and possess the qualities of a competent person in order to practice in a teambase, direct patient care settings ${ }^{[7,35]}$. As all clinical pharmacists are not highly competent due to the lack of some kind of skills, abilities, and techniques, therefore, they need to develop those skills to provide all health care services effectively and efficiently. Lifelong learning and professional developments are essential aspects of the pharmacy profession ${ }^{[7]}$. To be a competent clinical pharmacist, one should have the traits of professionalism: good skills of communication, commitment to excellence, strong medical science background, honesty, and integrity, respect for others and compassion ${ }^{[36]}$. Here, the necessary qualities that would help clinical pharmacist to become a competent and trustworthy member of the health care system were discussed (fig. 2) ) $^{[37]}$.

\section{Strong basic medical sciences background:}

In order to be competitive in the international arena, a clinical pharmacist must be scientifically literate and should have a strong basic medical science background as the world has become more technology and science driven $^{[38]}$. Only a knowledge of science is not sufficient, but also knowledge of how science functions, evolves,

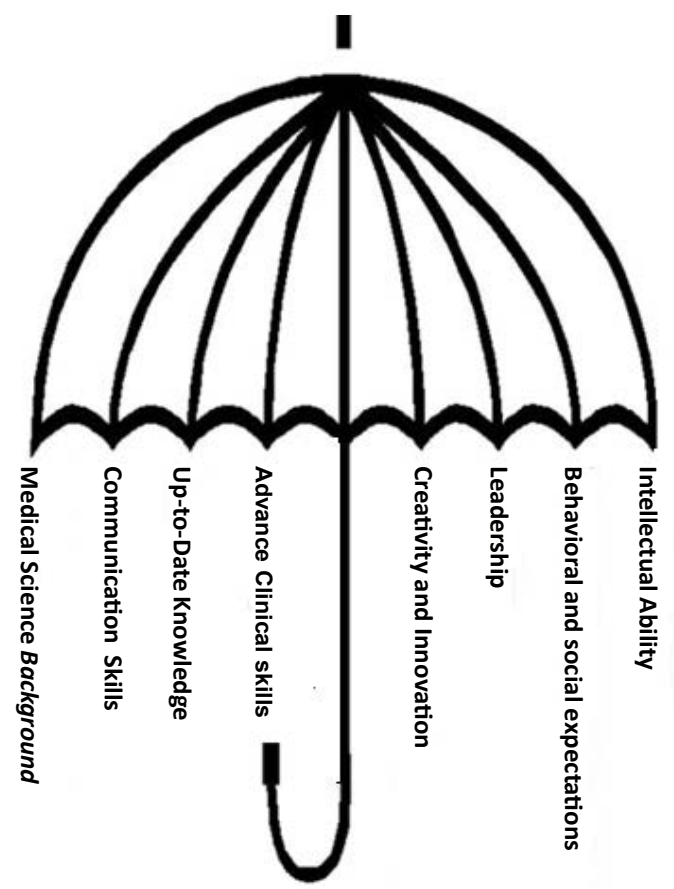

Fig. 2: Schematic of competent clinical pharmacist characteristics 
and how it relates to the society is also required for a clinical pharmacist to be scientifically literate ${ }^{[39]}$. A strong medical science background is necessary for a clinical pharmacist to be competitive because, without this, he/she cannot give effective therapy. It is a necessary precondition for creativity and innovation as a clinical pharmacist can only be able to give better and effective or totally innovative treatment if he/she will have a strong background in medical sciences. Basic medical sciences include subjects of physiology, anatomy, biochemistry, pharmacology, pathology, histology, clinical pharmacy, biopharmaceutics, biostatistics, industrial pharmacy, medicinal chemistry and some others.

Strong background in these subjects is compulsory for a clinical pharmacist to be competitive among his/ her professionals. The importance of strong medical sciences background is that it would provide safe and control practice opportunities, boots the knowledge and shape the acquisition of young clinical pharmacist skills ${ }^{[40,41]}$. For the clinical pharmacist to have strong medical sciences background, it is the responsibility of pharmacy boards and councils of each country to keep curricula of the pharmacy education up-to-date and should provide the students with basic clinical skills regardless of future practice settings since the fundamental elements exist in a variety of settings ${ }^{[5]}$. Besides these, teaching methods should be designed to instruct students how to become competent pharmacist, and pharmacy students should be exposed to the practice environment at an early stage in their curriculum that will help empower them to practice in close relationship with the patients ${ }^{[42]}$, so that they can meet the requirements and challenges of today and tomorrow health care problems.

\section{Communication skills:}

Better health services can only be provided by effective communication ${ }^{[43]}$. In 1997, the World Health Organization report entitled Preparing the Pharmacist of the Future: Curricular Development was released detailing the 7 essential roles of the pharmacist, one of which was "communicator"[44]. The Accreditation Council for Pharmacy Education standards and guidelines state that, pharmacy graduates should have good communication skills so that they can effectively communicate with physicians, nurses, patients and other members of health care team; administrative and support personnel; caregivers; policymakers and members of the community in order to provide a team approach to patient care ${ }^{[45]}$. Many studies have shown that there is a communication breakdown between the clinical pharmacist and patients because of poor communication skills ${ }^{[46]}$. If there will be a communication gap between clinical pharmacist and patient, it will results in a failure of achieving the desired treatment goals. Therefore, it is very important for the clinical pharmacist to improve his/her communication skills in order to provide better patient health care. As clinical pharmacist acts as a bridge between physician and the patient; their role as a communicator should not be ignored because doing that would lead to failure of the therapy and desired outcomes. Thus, it is the responsibility of clinical pharmacist to improve his/ her communication skills so that they can effectively communicate with physicians, nurses, patients, and other healthcare providers to ensure patient safety and optimal health outcomes ${ }^{[47]}$. With the help of training and education, communication skills of clinical pharmacist can be improved ${ }^{[48,49]}$.

\section{Up-to-date knowledge:}

Strong background of knowledge is important for every profession. Without strong knowledge background, the clinical pharmacist cannot compete with other health care professionals in this modern technology world. For clinical pharmacists to be competent, they must be able to know and remember about the drug nomenclature, side effects, adverse reaction and interactions between the medicines that are sometimeslife-and-death prerequisite for the job. Knowledge about new treatment and drug is essential for all organizations and/or countries to sustain economic progress ${ }^{[50]}$. The clinical pharmacist possessed indepth knowledge of physiology, biopharmaceutics and pharmacokinetics, pharmacology and therapeutics, physicochemical properties of drugs and excipients, adverse drug reactions and drug interactions. It is this complex, varied and integrated expert knowledge that qualifies them, and them alone, to make professional judgments relating to medicines ${ }^{[51]}$. Therefore, it is the professional duty of clinical pharmacist to provide best pharmaceutical care to the patient. If he/she will have no knowledge about the current and new medicines and treatments, then there will be a chance of failure of the therapy and the treatment goals will not be achieved. There are many ways by which clinical pharmacists can keep their knowledge up-to-date such as, reading medical magazines and books, watching the medical news, and videos, participating in the conferences, and by surfing the internet. 


\section{Creativity and innovation:}

In many books and business magazines, success stories of many firms and individuals are often featured in various parts of the world. In most cases, their success is not because of the result of hard work, but because of creatively utilization of new knowledge, advances in technology, and networks of relationships ${ }^{[50]}$. The world these days would appear quite different without creativity and innovation ${ }^{[52]}$. These two qualities are very important in every field to be able to compete in a labour market that has moved beyond skills. In this new era of competition, the clinical pharmacist should not only be a good follower instead, he/she must be a linchpin. A linchpin is an original thinker that invests their heart and soul into creating, inventing and leading without waiting around for someone to tell them what to do next. For creativity and innovation, it is important for the clinical pharmacists to have their own new ideas and strategies about work. One of the examples of creativity and innovation is the "Pharmaceutical care", which was presented by Hepler and Strand in $1989^{[3]}$. They gave this innovation because they had a strong medical science background and creativity in their thinking. For clinical pharmacists to have creativity and innovation in their work, it is important to have a strong background in medical sciences, be professional about their work, passionate, hardworking, and capable of thinking differently from other ordinary people and having a strong belief in his/her self.

\section{Leadership:}

Leadership is a quality and the process of influence in which one person take a significant number of people together in accomplishing a common task, and the effectiveness of leaders is determined by both the way they take their decisions and their outcomes and the level of their influence ${ }^{[53]}$. While a "Leader is an individual who significantly affects the behaviours, feelings, and thoughts of significant numbers of individuals"[54].

For a clinical pharmacist to be a competent person, he/she must possess the qualities of a good leader. A good leader always acts assertively, admits a mistake, challenges the status quo, communicates well, demonstrates integrity, encourages, innovates, and listens, make others feel important, provides good direction, and resolves conflicts. He/she has the ability to make decisions based upon sound logic and solid evidence, ability to create a solution to a problem for which there is no immediate or obvious answer. They have the ability to make accurate, evidence-based and timely decisions, and listen to others when decisions are questioned and are open to further evidence. Now the question is how a clinical pharmacist can become a leader? The first step to become a leader is that clinical pharmacist should identify what demotivates him/her and then tackle those problems. Second, they should identify the area where they can provide a different insight. Third, they should do their work to the best of their ability. Fourth, they should understand the culture of their workplace. Fifth, they should produce creativity in their work so that they can inspire others. Besides these, honesty, confidence, hardworking, good communication skills, keen to learn are the qualities that are required for clinical pharmacist in order to become a leader.

\section{Behavioural and social expectations:}

A competent pharmacist has the quality that he/she demonstrates a history of appropriate behaviour in personal actions, addresses disagreements with tact and avoids public altercations, exhibit the capacity to adapt to change readily, and adjust responses in dynamic, unpredictable situations, and accept constructive criticism and adapt behaviour. As there is an increased tendency of the population towards medication use and the increased self-service and mass merchandising of drugs, which pleaded that drugs need to be controlled ${ }^{[55]}$. Over many years, pharmacists have been trained in a more clinically-oriented fashion, researchers have established that patient counselling by pharmacist is important for improving appropriate medication use and achieving desired patient outcomes, pharmaceutical care as the mission of pharmacy has been embraced, and provision of patient counselling about medications by pharmacist has become required by law ${ }^{[56]}$. Although consultation provided by a pharmacist is reportedly beneficial ${ }^{[57-59]}$, but many researchers have shown that pharmacists do not provide enough counselling to the patient because of lack of enough time, having no demand from the patient, and lack of reimbursement. Clinical pharmacists tend to provide little information if counselling occurs ${ }^{[60,61]}$, particularly for repeat prescriptions or buying specific medication $^{[62]}$. The majority of the questions asked by the pharmacists are closed-ended questions and most pharmacists do not ask any questions from the patients ${ }^{[63]}$. While final counselling occurs when pharmacist transfers a prescription to the patient ${ }^{[64]}$. From this profile, it is not surprising that patients do 
not get enough information or get satisfied about the medications from their pharmacists. Patients have great expectation from clinical pharmacist to provide advice regarding the drugs and having good, friendly, and professional behaviour with them. Therefore, the clinical pharmacist should fulfil the expectations that the society is expecting from them. It is the professional responsibility of clinical pharmacist to have a good, friendly and professional behaviour with the patients, doctors, nurses and other staffs. For a clinical pharmacist to better meet patient needs, it is important for him/her to understand what role patients are expecting from them to perform in the relationship.

\section{Advanced clinical skills:}

A clinical pharmacist can provide better pharmaceutical care if he/she will have advanced level clinical skills. Here, advanced clinical skills mean that the clinical pharmacists have sufficient breadth and depth of therapeutic knowledge and experience and are expert in taking the patient medication history, reducing prescription errors, drug-drug interaction, drugfood interaction, dose adjustment, taking accurate medication history, reducing medication cost and patient counselling, which will result in desire highlevel patient outcomes. In most advance countries, the clinical pharmacist has the role to participate in taking patient medication history. The reason for this is that he/she has an advanced level clinical skill, thus can take better patient medication history which was previously done by a junior doctor ${ }^{[27,28]}$. In both multidisciplinary and specialty ward rounds, the clinical pharmacist now routinely participates with the explicit aim of reviewing and optimizing the appropriateness of medications prescribed $^{[65]}$.

In general, clinical pharmacists are highly trust worthy professionals and provide satisfied patient services ${ }^{[66]}$. Many studies have shown that there is a need for patient education (counselling) by the pharmacist. Therefore, the clinical pharmacist has the responsibility to provide detail oriented medication education to the patient. To provide satisfied patient services, clinical pharmacists are required to enhance their clinical skills. Clinical skills can be enhanced enormously by advancing in medical and therapeutic knowledge, regulating drug therapy for patients, ascertain ambiguous situation beyond his/her own proficiency or that require new medical information to conclude a decision. Delineate patient related problems and efficiently evaluate current therapy for those problems, using critical thinking and problem-solving skills through practice and be engaged in the provision of patient care for a sustained period.

\section{Intellectual ability:}

One of the good qualities of a competent clinical pharmacist is that he/she is always committed to knowledge acquisition, lifelong learning and or retrieval to serve patients. These include helping patients and others, producing quality work, fulfilling responsibilities and wanting to exceed expectations ${ }^{[67]}$. As an intellectual ability, it is the responsibility of clinical pharmacist to use critical thinking skills and problem-solving abilities to evaluate information from multiple sources and synthesize a plan of action, participate in self-programmatic assessment intended to sustain a continual improvement process, and be curious and pursue life-long learning.

Here in this review the clinical pharmacist was classified into three stages so that it is possible to better understand the role and responsibilities of clinical pharmacist at each stage, what the flaws are at each stage and what are their solution such as, the curricula of pharmacy in most countries is not well-updated that leads to the poor provision of knowledge and training to the future pharmacist and ultimately results in poor health care services. The teaching methods in the pharmacy institutions are traditional rote base, which ends in memorization and often eventual forgetting. Therefore, teachers should use problem-based learning or active learning, which involves student's engagement activities, critical analysis, problem-solving, providing higher-order thinking and providing feedback about the learning process to both students and teachers. There is also communication gap between the doctors and clinical pharmacists, which could be solve by specifying their roles and having cooperation with each other. There are many institutions, hospitals, and clinics, where the role of the clinical pharmacist is not well define, which needs to be specify. In most of the cases, the level of creativity and innovation are not up to the high level which also requisite to be improved.

To overcome such flaws and to provide better pharmaceutical care to the patient, the clinical pharmacist must be competent. Therefore, special efforts must be made to develop those qualities and characteristics that will make a clinical pharmacist a competent pharmacist.

\section{Acknowledgments:}

This work was supported by the National Science 
Foundation of China (Nos. 30973003 \& 30901993) and Administration of TCM of Jiangsu Province (No. LZ11093), and Teaching Reformation Research Project of China Pharmaceutical University 2017, and Teaching Reformation Research Project for Graduate of China Pharmaceutical University 2018.

\section{Conflicts of interest:}

All authors declare no conflict of interest.

\section{REFERENCES}

1. Bronkhorst E, Schellack N, Gous AGS, Pretorius JP. The need for pharmaceutical care in an intensive care unit at a teaching hospital in South Africa. S Afr J Crit Care 2014;30:41-4.

2. Wiedenmayer K, Summers RS, Mackie CA, Gous AGS, Everard M, Tromp D. Developing pharmacy practice: a focus on patient care. Geneva, Switzerland: World Health Organization, International Pharmaceutical Federation; 2006. p. 7.

3. Hepler CD, Strand LM. Opportunities and responsibilities in pharmaceutical care. Am J Hosp Pharm 1990;47(3):533-43.

4. Rowe AK, de Savigny D, Lanata CF, Victora CG. How can we achieve and maintain high-quality performance of health workers in low-resource settings? Lancet 2005;366:1026-35.

5. Hepler CD, Strand LM. Opportunities and responsibilities in pharmaceutical care. Am J Hosp Pharm 1990;47:533-43.

6. Stowasser DA, Allinson YM, O'Leary M. Understanding the Medicines Management Pathway. J Pharm Pract Res 2004;34:293-6.

7. American College of Clinical Pharmacy. The definition of clinical pharmacy. Pharmacotherapy 2008;28:816-17.

8. Barker KN, Valentino JG. On a political and legal foundation for clinical pharmacy practice. J Am Pharm Assoc 1972;12:202-6.

9. Leape LL, Cullen DJ, Clapp MD, Burdick E, Demonaco HJ, Erickson JI, et al. Pharmacist participation on physician rounds and adverse drug events in the intensive care unit. JAMA 1999;282:267-70.

10. Bond CA, Raehl CL, Franke T. Clinical pharmacist staffing in United States hospitals. Pharmacotherapy 2002;22:1489-99.

11. Beney J, Bero LA, Bond C. Expanding the roles of outpatient pharmacists: effects on health services utilisation, costs, and patient outcomes. Cochrane Database Syst Rev 2000;(3):Cd000336.

12. Francis J, Abraham S. Clinical pharmacists: Bridging the gap between patients and physicians. Saudi Pharm J 2014;22:600-2.

13. Kucukarslan SN, Peters M, Mlynarek M, Nafziger DA. Pharmacists on rounding teams reduce preventable adverse drug events in hospital general medicine units. Arch Intern Med 2003;163:2014-8.

14. Williams LA. Types of pharmacy/pharmacists. Int J Pharm Compd 2013;17:294-301.

15. Dembo MH. Applying educational psychology. 5th ed. New York, NY, US: Longman/Addison Wesley Longman; 1994. p. 27.

16. Marcy P. Psychology of learning for instruction. Needham
Heights, Massachusetts: Allyn Bacon Press; 2000. p. 8-9.

17. le Grand A, Hogerzeil HV, Haaijer-Ruskamp FM. Intervention research in rational use of drugs: a review. Health Policy Plan 1999;14:89-102.

18. Roberts AS. Community pharmacy: strategic change management. North Ryde, Australia: McGraw-Hill Education; 2007. p. 127.

19. Rosenthal M, Austin Z, Tsuyuki RT. Are pharmacists the ultimate barrier to pharmacy practice change? Can Pharm J 2010;143:37-42.

20. Singleton JA, Nissen LM. Future-proofing the pharmacy profession in a hypercompetitive market. Res Social Adm Pharm 2014;10:459-68.

21. Bradberry JC, Droege M, Evans RL, Guglielmo JB, Knapp DA, Knapp KK, et al. Curricula then and now: an environmental scan and recommendations since the commission to implement change in pharmaceutical education. Report of the 2006-2007 Academic Affairs Committee. Am J Pharm Educ 2007;71:S10.

22. American Association of Colleges of Pharmacy. Educational Outcomes. Available from: http://sitefinityuc.blob.core. windows.net/pharm-dev/docs/default-source/Program/capeeducational-outcomes-2013.pdf?sfvrsn=fc9e7940_0.

23. Fejzic J, Barker M. 'The readiness is all' - Australian pharmacists and pharmacy students concur with Shakespeare on work readiness. Pharm Educ 2015;15:76-82.

24. Frankel GE, Austin Z. Responsibility and confidence: Identifying barriers to advanced pharmacy practice. Can Pharm J 2013;146:155-61.

25. Brazeau GA, Meyer SM, Belsey M, Bednarczyk EM, Bilic S, Bullock $\mathrm{J}$, et al. preparing pharmacy graduates for traditional and emerging career opportunities. Am J Pharm Educ 2009;73:157.

26. Reta A, Dashtaei A, Lim S, Nguyen T, Bholat MA. Opportunities to improve clinical outcomes and challenges to implementing clinical pharmacists into health care teams. Prim Care 2012;39:615-26.

27. Hebron B, Jay C. Pharmaceutical care for patients undergoing elective ENT surgery. Pharm J 1998;260:65-6.

28. Gleason KM, Groszek JM, Sullivan C, Rooney D, Barnard C, Noskin GA. Reconciliation of discrepancies in medication histories and admission orders of newly hospitalized patients. Am J Health Syst Pharm 2004;61:1689-95.

29. Bassett-Jones N. The paradox of diversity management, creativity and innovation. Creat Innov Manag 2005;14:169-75.

30. Gurteen D. Knowledge, creativity and innovation. J Know Manag 1998;2:5-13.

31. The pharmacist shortage: where do we stand? Available from: http://www.medscape.com/viewarticle/521115_3.

32. Mott DA. Pharmacist job turnover, length of service, and reasons for leaving, 1983-1997. Am J Health Syst Pharm 2000;57:975-84.

33. Council on credentialing in pharmacy. Credentialing in pharmacy [cited 2016 Oct 28]. Available from: https://www. aacp.org/resource/council-credentialing-pharmacy-ccp.

34. Goodwin SD, Kane-Gill SL, Ng TMH, Melroy JT, Hess MM, Tallian K, et al. Rewards and advancements for clinical pharmacists. Pharmacotherapy 2010;30:68e-85e.

35. Mitchell P, Wynia M, Golden R, McNellis B, Okun S, Webb $\mathrm{CE}$, et al. Core principles and values of effective team-based health care. Washington, DC: Institute of Medicine; 2012. 
36. American College of Clinical Pharmacy, Roth MT, Zlatic TD. Development of student professionalism. Pharmacotherapy 2009;29:749-56.

37. Hammer DP, Berger BA, Beardsley RS, Easton MR. Student Professionalism. Am J Pharm Educ 2003;67:96.

38. National Science Board. Science and Engineering Indicators 2010. Arlington, VA: National Science Foundation (NSB 10$01) ; 2010$.

39. Lederman NG. Students' and teachers' conceptions of the nature of science: A review of the research. J Res Sci Teach 1992;29:331-59.

40. Issenberg SB, McGaghie WC, Hart IR, Mayer JW, Felner JM, Petrusa ER, et al. Simulation technology for health care professional skills training and assessment. JAMA 1999;282:861-6.

41. Gaba D. Human work environment and simulators, Anesthesia. $5^{\text {th }}$ ed. Philadelphia: Churchill Livingstone; 2000.

42. Lawrence L, Sherman J, Adams E, Gandra S. Pharmacy students' perceptions of pharmaceutical care in retail and clinic settings. Am J Pharm Educ 2004;68:4.

43. Wallman A, Vaudan C, Sporrong SK. Communications training in pharmacy education, 1995-2010. Am J Pharm Educ 2013;77:36.

44. WHO. The role of the pharmacist in the health care system: preparing the future pharmacist: curricular development: report of a third WHO Consultative Group on the Role of the Pharmacist, Vancouver, Canada, 27-29 August 1997. Available from: http://apps.who.int/iris/handle/10665/63817.

45. Accreditation Council for Pharmacy Education. Available from: https://www.acpe-accredit.org/pdf/S2007Guidelines2.0 ChangesIdentifiedInRed.pdf.

46. Parkhurst C. Assessing and improving students' verbal communication abilities in pharmacy courses. Am J Pharm Educ 1994;58:50-5.

47. Boesen KP, Herrier RN, Apgar DA, Jackowski RM. Improvisational exercises to improve pharmacy students' professional communication skills. Am J Pharm Educ 2009;73:35.

48. Kimberlin CL. Communicating With Patients: Skills Assessment in US Colleges of Pharmacy. Am J Pharm Educ 2006;70:67.

49. Mesquita AR, Lyra DP, Jr Brito GC, Balisa-Rocha BJ, Aguiar PM, de Almeida Neto AC. Developing communication skills in pharmacy: a systematic review of the use of simulated patient methods. Patient Educ Couns 2010;78:143-8.

50. Kandampully J. Innovation as the core competency of a service organisation: the role of technology, knowledge and networks. Eur J Innov Manag 2002;5:18-26.

51. Harding G, Taylor K. Pharmacy's strength lies in its blend of clinical, scientific and social skills. Pharm J 2004;273:126.
52. Legrenzi P. Creativity and innovation. Bologna: Il Mulino; 2013. p. 6.

53. Brousseau KR, Driver MJ, Hourihan G, Larsson R. The seasoned executive's decision-making style. Harv Bus Rev 2006;84:110-21.

54. Gardner H, Laskin E. Leading Minds: An Anatomy of Leadership. New York City, New York, United States: Basic Books; 1996. p. 5.

55. Linn LS, Davis MS. Occupational orientation and overt behaviour-the pharmacist as drug adviser to patients. Am J Public Health 1973;63:502-8.

56. Schommer JC. Patients' Expectations and Knowledge of Patient Counselling Services that Are Available from Pharmacists. Am J Pharm Educ 1997;61:402-6.

57. McKenney J, Brown D, Necsary R, Reavis H. Effect of pharmacist drug monitoring and patient education on hypertensive patients. J Contemp Pharm Pract 1978;1:50-6.

58. Davis NM, Cohen MR. Counselling reduces dispensing accidents. Am Pharm 1992;32:22.

59. Hammarlund ER, Ostrom JR, Kethley AJ. The effects of drug counseling and other educational strategies on drug utilization of the elderly. Med Care 1985;23:165-70.

60. Svarstad BL, Bultman DC, Mount JK. Patient counseling provided in community pharmacies: effects of state regulation, pharmacist age and busyness. J Am Pharm Assoc 2004;44:22-9.

61. Eng HJ, Bulfer BA, Doering PL, Kimberlin CL. Assessment of the Florida Pharmacist Self-care Consultant Law Using a Trained Shopper Method. J Pharm Mark Manage 1991;5:27-52.

62. Puumalainen II, Peura SH, Kansanaho HM, Benrimoj CSI, Airaksinen MSA. Progress in patient counselling practices in Finnish community pharmacies. Int $\mathrm{J}$ Pharm Pract 2005;13:149-56.

63. Sleath B. Pharmacist question-asking in New Mexico community pharmacies. Am J Pharm Educ 1995;59:374-9.

64. Schommer JC, Wiederholt JB. A field investigation of participant and environment effects on pharmacist-patient communication in community pharmacies. Med Care 1995;33:567-84.

65. Ng J, Harrison J. Key performance indicators for clinical pharmacy services in New Zealand public hospitals: stakeholder perspectives. J Pharm Health Serv Res 2010;1:75-84.

66. Reid LD, Wang F, Young H, Awiphan R. Patients' satisfaction and their perception of the pharmacist. J Am Pharm Assoc 1999;39:835.

67. Chisholm MA, Cobb H, Duke L, McDuffie C, Kennedy WK. Development of an instrument to measure professionalism. Am J Pharm Educ 2006;70:85. 